\title{
A COMPARTIMENTAÇÃO HORIZONTAL NA SEGURANÇA CONTRA INCÊNDIO
}

\author{
Thiago Menezes de Andrade ${ }^{1}$ \\ Valdir Pignatta Silva ${ }^{2}$
}

\section{RESUMO}

No Brasil, a segurança contra incêndio é pouco pesquisada e, não raramente, mal aplicada. A falta de pesquisa é ainda mais visível quando se tratam das hipóteses, exigências e limites de compartimentação. A compartimentação vertical e horizontal, ou seja, o ato de impedir que o fogo, caso se inicie, não se propague além do local de origem, são exigências que minimizam a ação do fogo, quer na proteção à vida, quer na do patrimônio. Apesar de fundamental na segurança contra incêndio, não há norma brasileira sobre esse tema. Há exigências de alguns Corpos de Bombeiros estaduais por meio de suas instruções técnicas. O objetivo deste trabalho é contribuir com a elaboração de uma futura norma brasileira, analisando as exigências internacionais e, mais do que isso, o avanço científico e os critérios adotados em diversos países e comparando ao que se tem no Brasil. Por se tratar de um tema longo de ser abordado, este artigo visará a compartimentação horizontal.

Palavras-Chave: Incêndio. Compartimentação horizontal. Segurança contra incêndio.

\footnotetext{
${ }^{1}$ Mestre em Engenharia Civil pela Escola Politécnica da Universidade de São Paulo. E-mail: thiagomandrade@usp.br

2 Professor Doutor da Escola Politécnica da Universidade de São Paulo. E-mail: valpigss@usp.br
} 


\title{
THE HORIZONTAL COMPARTMENTATION AT FIRE SAFETY
}

\begin{abstract}
In Brazil, the fire safety is poorly researched and not infrequently misapplied. The lack of research is even more visible when regards requirements and compartmentation limits. The vertical and horizontal compartmentation, i.e. the act of preventing the fire, when start, does not spread beyond the site of origin, are requirements that minimize the action of the fire or in the protection of life, whether in equity. Although critical in fire safety, there is no Brazilian standard on this issue. There are requirements of some state Fire Departments through its technical instructions. The objective of this work is to contribute to the development of a future Brazilian standard, analyzing international requirements and, more than that, the scientific advancement and the criteria adopted in several countries and comparing to what we have in Brazil. Because it is a long topic to be addressed, this article will aim only to horizontal compartmentation.
\end{abstract}

Keywords: Fire. Horizontal compartmentation. Fire safety.

Artigo Recebido em 18/06/2018 e Aceito em 27/08/2018 
Revista Científica do Corpo de Bombeiros Militar de Pernambuco

Seção 1 - Artigos Técnico Científicos

Artigo publicado no Vol.04 №10 - Edição de JUL a DEZ 2018 - ISSN 2359-4837(online)

Versão on-line disponível em: http://www.revistaflammae.com

\section{INTRODUÇÃO}

Com o constante crescimento e adensamento das grandes cidades em todo o mundo, a segurança contra o incêndio se torna cada vez mais importante.

Por mais que se tomem medidas para reduzir as causas dos incêndios, tais como, melhoria das instalações elétricas, manutenção adequada de equipamentos, instalação de detectores de fumaça, dentre muitos outros, a segurança absoluta contra o incêndio é impossível. Sendo assim, uma vez que o incêndio se inicia, é essencial que o projeto da edificação seja desenvolvido com fins de facilitar o abandono de todas as pessoas do seu interior (SILVA, 2014).

Os grandes incêndios acompanham a história da humanidade, causando enormes perdas materiais e principalmente grande perda de vidas humanas.

Dos grandes incêndios com dimensões urbanas, como Roma no ano 64, Londres (1666), Hamburgo (1842), Chicago (1871) e Boston (1872), que não devem se repetir nas cidades atuais, principalmente pela modernização da urbanização e pela presença dos automóveis, que criou uma hierarquização das ruas e, consequente, aumentou o afastamento das edificações (GILL; NEGRISOLO; OLIVEIRA, 2008). Aos incêndios em grandes edificações, tais como: Opera Rhoads (Boyertown, Pensilvânia - 1908), Lake View Elementary School (Cleveland, Ohio - 1908), Triangle Shirtwaist Company (Nova York 1911), e os brasileiros, Gran Circo Norte-Americano (Niterói, RJ - 1961), Edifício Andraus (São Paulo, SP - 1972) e Edifício Joelma (São Paulo, SP 1974) (SILVA, 2014). Chegando nos recentes incêndios da Boate Kiss (2013) e do Edifício Wilton Paes de Almeida (2018).

Esses edifícios não eram compartimentados e são exemplos que demonstram como a proteção contra incêndio é importante e porque a cada ano novos sistemas de proteção são desenvolvidos e milhões são gastos na segurança das edificações novas e antigas. 
Segundo a ABNT NBR 14432:2001, existem dois tipos de proteções contra incêndio: a proteção ativa, que é todo e qualquer tipo de proteção que precisa ser ativada (manualmente ou automaticamente) em resposta aos estímulos causados pelo incêndio (geralmente composta por instalações prediais de dispositivos contra incêndio); e a proteção passiva, que são todas as medidas incorporadas à edificação, presentes naturalmente durante o uso comum do edifício, e que reage passivamente ao desenvolvimento do incêndio, seja estabelecendo condições pouco propícias ao crescimento e propagação do fogo, propiciando a resistência ao fogo necessária a um elemento construtivo, e facilitando o abandono dos usuários do edifício e o ingresso das equipes de combate ao fogo.

A compartimentação na proteção passiva tem a função de evitar, ou retardar, a propagação do fogo entre compartimentos. Para isso, atenta-se para diversas características do projeto da edificação, dentre eles: arquitetônicas (como as dimensões dos espaços fechados, concepção das fachadas, localização dos elementos de compartimentação, rotas de fuga); medidas urbanísticas (como a distância mínima entre as edificações); projeto de estruturas da edificação e seu desempenho em situação de incêndio; a própria construção (vedando quaisquer passagem entre compartimentos) (COSTA; ONO; SILVA, 2005).

O objetivo deste trabalho é discorrer sobre a função da compartimentação horizontal e compreender como alguns países ao redor do mundo entendem, definem e legislam sobre ela visando a segurança contra $o$ incêndio.

A principal importância e contribuição deste trabalho é a possibilidade de verificar qual é o entendimento com relação à segurança contra o incêndio de países de quatro continentes, cujos métodos construtivos são distintos e que possuem diferenças culturais no âmbito da construção civil. Por intermédio deste estudo, é possível se visualizar os conceitos sobre compartimentação 
Revista Científica do Corpo de Bombeiros Militar de Pernambuco Seção 1 - Artigos Técnico Científicos

Artigo publicado no Vol.04 №10 - Edição de JUL a DEZ 2018 - ISSN 2359-4837(online)

Versão on-line disponível em: http://www.revistaflammae.com

horizontal de forma mais global e, aproveitando a experiência internacional, colaborar com uma futura norma brasileira.

\section{O CONCEITO DE COMPARTIMENTAÇÃO E SUA IMPORTÂNCIA}

Segundo SILVA (2014), um compartimento é uma edificação, ou parte de uma edificação podendo conter um ou mais cômodos, espaços, corredores e até mesmo andares, construídos de tal forma a evitar a propagação de um incêndio para as áreas ou os edifícios adjacentes. A compartimentação de uma área ou de um edifício é garantida pela existência de elementos de compartimentação ou por um adequado afastamento entre duas aberturas ou edificações.

Para que um elemento construtivo seja considerado em elemento de compartimentação é necessário que ele possua simultaneamente três qualidades: isolamento térmico, estanqueidade e estabilidade ao fogo.

A compartimentação pode ser subdividida em duas: a compartimentação horizontal, cuja função é evitar a propagação horizontal do incêndio, e pode ser exemplificada pela área máxima de um compartimento, e a compartimentação vertical, cuja função é evitar a propagação vertical do incêndio, ou seja, evitar que o incêndio passe para um o andar superior ao de origem.

Este artigo se restringirá à compartimentação horizontal. Essa divisão da edificação é de extrema importância tanto para o combate ao incêndio, quanto para a redução de danos à vida e a bens materiais pois, por meio delas, é possível reduzir o alastramento do incêndio e, consequentemente, reduzir as dimensões do sinistro.

As definições apresentadas a seguir são similares, podendo ou não abranger todos os itens, em diversas normas da Associação Brasileira de Normas Técnicas (ABNT), tais como:

- $\quad$ ABNT NBR 13860:1997 - Glossário de termos relacionados com a segurança contra incêndio; 
Revista Científica do Corpo de Bombeiros Militar de Pernambuco Seção 1 - Artigos Técnico Científicos

Artigo publicado no Vol.04 №10 - Edição de JUL a DEZ 2018 - ISSN 2359-4837(online)

Versão on-line disponível em: http://www.revistaflammae.com

- $\quad$ ABNT NBR 14323:2013 - Projeto de estruturas de aço e de estruturas mistas de aço e concreto de edifícios em situação de incêndio;

- $\quad$ ABNT NBR 14432:2000 - Exigências de resistência ao fogo de elementos construtivos de edificações - Procedimento;

- $\quad$ ABNT NBR 15200:2012 - Projeto de estruturas de concreto em situação de incêndio.

Além de outros códigos nacionais e estrangeiros, tais como:

- Decreto $N^{\circ} 56.819$ de 10 de março de 2011 - Estado de São Paulo;

- Instrução Técnica $N^{\circ} 3$ de 2015 - Corpo de Bombeiros do Estado de São Paulo;

- $\quad$ Portaria $n^{\circ}$ 1532/2008 - Autoridade Nacional de Proteção Civil (ANPC Portugal);

- $\quad$ The Building Regulations 2010 -HM Government - Inglaterra;

- $\quad$ Code of Practice for Fire Safety in Buildings 2011 - Buildings Department (Hong Kong);

- International Building Code 2012 - International Code Council (ICC Estados Unidos).

\subsection{Isolamento térmico}

$\mathrm{O}$ isolamento térmico pode ser definido pela capacidade de um elemento, seja ele estrutural ou não, de limitar a passagem de calor através de sua espessura com o objetivo de evitar a combustão espontânea de materiais fora do compartimento onde o incêndio se iniciou.

A garantia do isolamento térmico é obtida por meio de ensaios seguindo procedimentos normatizados, ou, quando possível, empregando equações teóricas normatizadas.

Para as normas brasileiras ABNT NBR 5628:2001 e ABNT NBR 10636:1989, um elemento pode ser considerado isolante se tiver a capacidade de garantir um aumento máximo da temperatura na face oposta ao incêndio de $140{ }^{\circ} \mathrm{C}$, em média, ou $180^{\circ} \mathrm{C}$, em qualquer ponto. 
Revista Científica do Corpo de Bombeiros Militar de Pernambuco Seção 1 - Artigos Técnico Científicos

Artigo publicado no Vol.04 №10 - Edição de JUL a DEZ 2018 - ISSN 2359-4837(online)

Versão on-line disponível em: http://www.revistaflammae.com

\subsection{Estanqueidade}

A estanqueidade pode ser definida como a capacidade de um elemento evitar a formação de fissuras que propicie a passagem de chamas ou gases quentes através dele.

A garantia da estanqueidade é atualmente obtida experimentalmente por meio de procedimentos normatizados na ABNT NBR 10636:1989. Esse procedimento consiste em observar a formação de fissuras em um elemento e verificar se a fissura tem uma dimensão suficiente para ignizar um chumaço de algodão próximo à superfície.

\subsection{Estabilidade ao fogo}

A estabilidade ao fogo pode ser definida como a capacidade de um elemento em manter suas características estruturais durante um certo período de tempo. Esse período de tempo é apresentado nas normas e códigos como o tempo requerido de resistência ao fogo (TRRF) que pode se referenciar tanto a um elemento, quanto à estrutura como um todo.

\subsection{Tempo Requerido de Resistência ao Fogo (TRRF)}

O TRRF consiste em um tempo mínimo, geralmente apresentado em minutos, que um elemento deve garantir seu isolamento térmico, sua estanqueidade e sua estabilidade ao fogo, ao ser submetido a um incêndiopadrão em ensaios de resistência ao fogo.

O incêndio-padrão é representado por uma curva logarítmica de aumento de temperatura em função do tempo, adotada internacionalmente, cuja função não é simular um incêndio real, mas sim representar um acréscimo de temperatura considerado difícil de ser atingido no TRRF.

O TRRF é fornecido, no Brasil, pelas Instruções Técnicas dos Corpos de Bombeiro de cada estado, ou na ausência delas, pela ABNT NBR 14432:2001. O risco de incêndio é a composição do perigo de ignição e de suas consequências. Esse tempo mínimo de resistência é determinado de acordo 
Revista Científica do Corpo de Bombeiros Militar de Pernambuco Seção 1 - Artigos Técnico Científicos

Artigo publicado no Vol.04 №10 - Edição de JUL a DEZ 2018 - ISSN 2359-4837(online)

Versão on-line disponível em: http://www.revistaflammae.com

com um risco associado à ocupação da edificação (representando o perigo de início de incêndio) e à sua altura (representando as consequências do sinistro). É importante ressaltar que esse tempo não é tempo real. Trata-se de uma referência, empregada em ensaios, para facilitar os projetos em geral.

\subsection{Tempo de Resistência ao Fogo (TRF)}

O TFR consiste no tempo máximo, normalmente dado em minutos, cujo elemento em questão garante seu isolamento térmico, sua estanqueidade e sua estabilidade ao fogo na presença de um incêndio-padrão (COSTA, 2008).

É importante entender a diferença entre TRRF e TRF. Um elemento deve possuir um TRF superior ou igual ao seu TRRF, uma vez que o TRRF é um valor mínimo solicitado em norma para o dado elemento, enquanto o TRF é seu valor real.

\subsection{Compartimentação horizontal}

Como já citado anteriormente, a compartimentação horizontal é aquela que impede ou retarda a propagação horizontal entre compartimentos adjacentes em um mesmo pavimento. Essa medida é importante, pois reduz a área afetada pelo incêndio e, consequentemente, facilita o combate e reduz as perdas.

Os elementos presentes na compartimentação horizontal são:

- Paredes cujas características (material e espessura) garantem o TRRF normatizado. Esse tempo normalmente é o TRRF das estruturas, mas há valores mínimos a respeitar;

- Portas corta fogo (PCF) dimensionadas de acordo com o TRRF normatizado. Da mesma forma que para as paredes, o TRRF das portas corta fogo, geralmente, seguem os TRRF das estruturas, mas podem variar a depender do país e finalidade (porta de escada enclausurada, porta de parede de compartimentação etc.). Mesmo dentro do nosso país, há diferenças; 
Revista Científica do Corpo de Bombeiros Militar de Pernambuco

Seção 1 - Artigos Técnico Científicos

Artigo publicado no Vol.04 №10 - Edição de JUL a DEZ 2018 - ISSN 2359-4837(online)

Versão on-line disponível em: http://www.revistaflammae.com

- Distância mínima horizontal entre aberturas para o exterior de compartimentos adjacentes (Figura 1), ou, opcionalmente, o emprego de abas verticais para minimizar a propagação horizontal do incêndio (Figura 1) Esse valor varia a depender do país e mesmo dentro do Brasil;

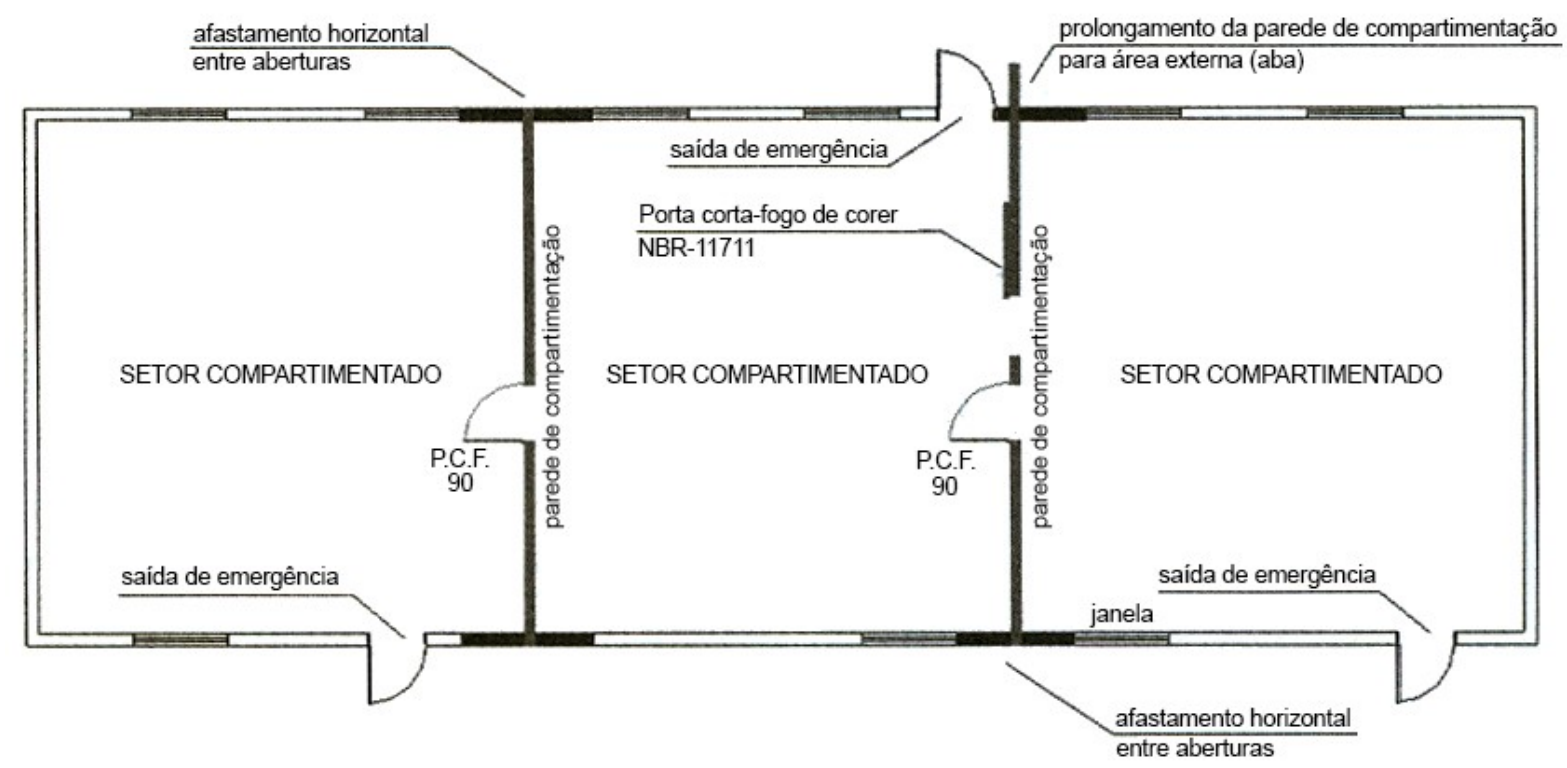

Figura 1 - Exemplo dos detalhes da compartimentação horizontal

Fonte: MARCATTI; COELHO FILHO; BERQUÓ FILHO, 2008 (adaptada)

- Selagem de toda e qualquer ligação horizontal entre dois compartimentos adjacentes, como por exemplo, passagem de tubulações, dutos e shafts, com a utilização de materiais incombustíveis e preenchimento dos vãos com substâncias igualmente incombustíveis. Geralmente, devem respeitar os TRRF dos elementos de compartimentação em que eles serão aplicados.

\subsection{Distância de isolamento de risco}

A distância de isolamento de risco é a distância mínima entre fachadas de dois edifícios de maneira a controlar o risco de propagação do incêndio por radiação, convecção e transmissão de chamas, de maneira que o incêndio não passe de uma edificação para a outra (MARCATTI; COELHO FILHO; BERQUÓ FILHO, 2008). 
Revista Científica do Corpo de Bombeiros Militar de Pernambuco Seção 1 - Artigos Técnico Científicos

Artigo publicado no Vol.04 №10 - Edição de JUL a DEZ 2018 - ISSN 2359-4837(online)

Versão on-line disponível em: http://www.revistaflammae.com

A Instrução Técnica $n^{\circ} 7$ (2015) do Corpo de Bombeiros de São Paulo fornece um procedimento para a determinação de tal distância mínima, com base na norma norte-americana NFPA 80A (1996).

Um ponto importante a ser observado é que, nas instruções técnicas dos corpos de bombeiros, a distância mínima entre fachadas é tratada como isolamento de risco, não sendo considerada como parte da compartimentação horizontal. Os autores acreditam que, apesar de obviamente isolar o risco, se a distância mínima não for respeitada, o fogo pode se propagar para o outro edifício e, pelo conceito, aumentando a área compartimentada.

Segundo Silva (2012) é fundamental dominar-se o conceito de compartimentação, também para a correta decisão sobre o valor a ser adotado como área de compartimento no uso do método do tempo equivalente SILVA et. al. (2017).

Este item não será estudado de forma mais aprofundada.

\section{EXIGÊNCIAS DE COMPARTIMENTAÇÃO HORIZONTAL}

De forma a homogeneizar os conhecimentos e preceitos apresentados em normas nacionais e estrangeiras, foi preciso inicialmente estudar e entender a visão de cada país sobre compartimentação horizontal, seus critérios e restrições.

Neste item serão apresentadas de forma individualizada as exigências de compartimentação horizontal presentes em normas ou códigos dos países selecionados. A seleção dos países foi realizada de maneira a se obter a visão mais globalizada possível do tema. Sendo assim chegou-se aos seguintes países e sua importância para a análise:

- Brasil: representante da América do Sul, possui uma engenharia focada em edificações de concreto, sua população possui um baixo poder aquisitivo e é o país para o qual este estudo está sendo feito. Uma vez que o Brasil não possui uma legislação unificada de segurança contra o incêndio, mais 
Revista Científica do Corpo de Bombeiros Militar de Pernambuco

Seção 1 - Artigos Técnico Científicos

Artigo publicado no Vol.04 №10 - Edição de JUL a DEZ 2018 - ISSN 2359-4837(online)

Versão on-line disponível em: http://www.revistaflammae.com

especificamente de compartimentação, adotou-se por padrão a legislação do Estado de São Paulo e as instruções técnicas do Corpo de Bombeiros do Estado de São Paulo, que são as mais avançadas do país. Sendo assim, quando esse texto se referir às normas brasileiras, entenda-se normas do Estado de São Paulo;

- Portugal: representante da Europa continental, possui a cultura mais próxima possível do Brasil e é um país com médio poder aquisitivo para os padrões europeus;

- Inglaterra: representante da Europa insular, possui uma cultura distinta da brasileira ou da portuguesa, possui um alto poder aquisitivo para os padrões europeus;

- Hong Kong: representante da Ásia, possui um altíssimo poder aquisitivo para a construção civil e possui a cultura mais distante de todos os países selecionados;

- $\quad$ Estados Unidos: representante da América do Norte, possui uma cultura mais próxima da inglesa, sua construção civil é focada em madeira para edificações pequenas e aço para edificações grandes, possuindo características e cultura construtiva únicas, além de possuir um alto poder aquisitivo.

Por fim, para facilitar a comparação das máximas áreas compartimentadas, que é o principal fator da compartimentação horizontal, os autores escolheram doze grupos distintos de tipo de uso das edificações. Sendo eles:

- Habitações; estacionamentos; administrativos ou serviços; instituições de ensino; hospitais ou casas de repouso; locais de reunião de público; serviços de hospedagem; comerciais; museus ou galerias de arte; bibliotecas ou arquivos; indústrias; depósitos. 
Revista Científica do Corpo de Bombeiros Militar de Pernambuco

Seção 1 - Artigos Técnico Científicos

Artigo publicado no Vol.04 №10 - Edição de JUL a DEZ 2018 - ISSN 2359-4837(online)

Versão on-line disponível em: http://www.revistaflammae.com

\subsection{Brasil}

No Brasil, para que a compartimentação seja garantida deve-se seguir as seguintes regras:

- As paredes e entrepisos de compartimentação devem respeitar as exigências para estabilidade, estanqueidade e isolamento térmico para o TRRF estipulado para cada tipo de edificação;

- $\quad$ As PCF devem ser dimensionadas de acordo com a edificação por meio da norma ABNT NBR 11742:2014, tendo seu TRRF limitado em cento e vinte minutos, diferentemente do TRRF das estruturas, que pode ser superior. Caso a PCF dê acesso ao pavimento ela deve possuir resistência mínima de 90 min, ou se possuir antecâmara, 60 min, independentemente do TRRF da estrutura;

- Todas as passagens entre compartimentos devem ser fechadas utilizando-se de selos corta fogo ou vedadores corta fogo com o TRRF equivalente ao TRRF do elemento de compartimentação em que está sendo instalado;

- As selagens das ligações entre compartimentos de passagens das instalações de serviço não podem possuir TRRF inferior a $60 \mathrm{~min}$. Devendo ser produzidas com materiais ensaiados e caracterizados como resistentes ao fogo por meio dos procedimentos previstos na ABNT NBR 6479:1992. Os tubos plásticos com dimensões superiores a $40 \mathrm{~mm}$ devem receber uma proteção adicional para que, após serem consumidos pelo fogo, a selagem seja capaz de fechar o buraco remanescente e que as selagens não sejam destruídas pela ação do fogo;

- Para a passagem de dutos de ventilação e ar-condicionado deve-se utilizar registros corta fogo automáticos, com TRRF de ao menos $120 \mathrm{~min}$, ou devem ser constituídos de material com resistência ao fogo equivalente à parede ou entrepiso de compartimentação em que está instalada;

- Paredes corta fogo e prumadas de ventilação permanentes devem possuir TRRF mínimos de 60 min e 30 min, respectivamente. 
Revista Científica do Corpo de Bombeiros Militar de Pernambuco Seção 1 - Artigos Técnico Científicos

Artigo publicado no Vol.04 №10 - Edição de JUL a DEZ 2018 - ISSN 2359-4837(online) Versão on-line disponível em: http://www.revistaflammae.com

- Deve-se garantir uma distância mínima horizontal entre aberturas para o exterior de compartimentos adjacentes de dois metros, podendo ser substituída por uma prolongação da parede de compartimentação com ao menos noventa centímetros. Essa distância também pode ser substituída pelo uso de portas/vedadores/vidros corta fogo de resistência equivalente à da estrutura;

- Os compartimentos devem possuir uma área máxima, podendo possuir múltiplos pavimentos.

As áreas máximas permitidas para um compartimento, são apresentadas na Instrução Técnica № 09 de 2015 do Corpo de Bombeiros da Polícia Militar

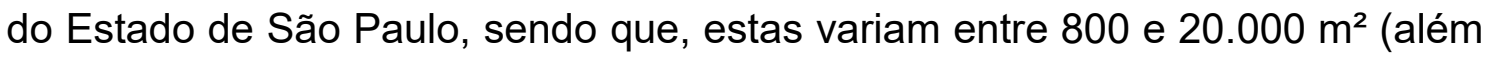
de áreas ilimitadas para alguns tipos de edificações).

A Tabela 1 apresenta os valores que essa norma determina como área máxima para um compartimento, baseado na altura da edificação e no seu tipo de uso.

Tabela 1 - Área Máxima de Compartimentação para o Estado de São Paulo

\begin{tabular}{|c|c|c|c|c|c|c|c|c|}
\hline & & & \multicolumn{6}{|c|}{ Altura da Edificação } \\
\hline & & & Térrea & $\leq 6 \mathrm{~m}$ & $\leq 12 \mathrm{~m}$ & $\leq 23 \mathrm{~m}$ & $\leq 30 \mathrm{~m}$ & $>30 \mathrm{~m}$ \\
\hline \multirow{18}{*}{ 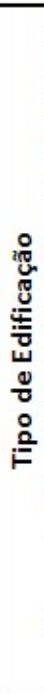 } & \multicolumn{2}{|l|}{ Habitações } & - & - & - & - & - & - \\
\hline & \multicolumn{2}{|c|}{ Estacionamentos } & - & - & - & - & - & - \\
\hline & \multicolumn{2}{|c|}{ Administrativos ou Serviços } & $5.000^{*}$ & $2.500^{*}$ & 1.500 & 1.000 & 800 & 1.500 \\
\hline & \multicolumn{2}{|c|}{ Instituições de Ensino } & - & - & - & - & - & - \\
\hline & \multicolumn{2}{|c|}{ Hospitais ou Casas de Repouso } & - & - & - & 2.000 & 1.500 & 1.000 \\
\hline & \multicolumn{2}{|c|}{ Locais de Reunião de Público } & - & - & - & $2.000 * *$ & $1.500^{* *}$ & $1.000^{* *}$ \\
\hline & \multicolumn{2}{|c|}{ Serviços de Hospedagem } & - & 5.000 & 4.000 & 3.000 & 1.500 & 1.500 \\
\hline & \multirow{2}{*}{ Comerciais } & Comércios em geral & $10.000^{*}$ & $5.000^{*}$ & 2.500 & 2.000 & 1.500 & 1.500 \\
\hline & & Shoppings & $5.000^{*}$ & $2.500^{*}$ & 1.500 & 1.000 & 800 & 1.000 \\
\hline & \multicolumn{2}{|c|}{ Museus ou Galerias de Arte } & - & - & - & - & - & - \\
\hline & \multicolumn{2}{|c|}{ Bibliotecas ou Arquivos } & - & - & - & - & - & - \\
\hline & \multirow{3}{*}{ Indústrias } & Carga de incêndio $\leq 300 \mathrm{MJ} / \mathrm{m}^{2}$ & - & 10.000 & 5.000 & 3.000 & 1.500 & 2.000 \\
\hline & & Carga de incêndio $\leq 1.200 \mathrm{MJ} / \mathrm{m}^{2}$ & - & 10.000 & 5.000 & 3.000 & 1.500 & 2.000 \\
\hline & & Carga de incêndio $>1.200 \mathrm{MJ} / \mathrm{m}^{2}$ & $7.500^{*}$ & 5.000 & 3.000 & 1.500 & 1.000 & 1.500 \\
\hline & \multirow{4}{*}{ Depósitos } & Materiais incombustiveis & - & - & - & - & - & - \\
\hline & & Carga de incêndio $\leq 300 \mathrm{MJ} / \mathrm{m}^{2}$ & $10.000^{*}$ & 5.000 & 3.000 & $1.500^{*}$ & 2.000 & 1.500 \\
\hline & & Carga de incêndio $\leq 1.200 \mathrm{MJ} / \mathrm{m}^{2}$ & $7.500^{*}$ & 3.000 & 2.000 & 2.500 & 1.500 & 1.000 \\
\hline & & Carga de incêndio $>1.200 \mathrm{MJ} / \mathrm{m}^{2}$ & $4.000^{*}$ & 2.500 & 1.500 & 2.000 & 1.500 & 1.000 \\
\hline
\end{tabular}

Fonte: Corpo de Bombeiros da Polícia Militar do Estado de São Paulo, 2015c (adaptada) 
Revista Científica do Corpo de Bombeiros Militar de Pernambuco Seção 1 - Artigos Técnico Científicos

Artigo publicado no Vol.04 №10 - Edição de JUL a DEZ 2018 - ISSN 2359-4837(online)

Versão on-line disponível em: http://www.revistaflammae.com

Pode se observar que para algumas ocupações, por exemplo em serviços ou shoppings, a área máxima reduz com o aumento da altura da edificação, porém, a partir de determinada altura, a área máxima aumenta. Isso acontece porque a partir dessa altura há exigência extras de segurança contra incêndio, como por exemplo, a obrigatoriedade da instalação de chuveiros automáticos. Isso alerta que as IT's devem ser sempre empregadas em conjunto.

Segundo o decreto $n^{\circ} 56.819$ do Estado de São Paulo de 2011 em praticamente todos os edifícios com altura inferior a trinta metros, cuja área máxima de compartimentação é obrigatória (determinada por meio desse mesmo decreto), é possível substituir a restrição de área pela utilização de chuveiros automáticos, sendo algumas vezes necessário associá-los à detectores de incêndio. Alguns exemplos em que nunca é possível realizar esta substituição são edifícios especiais como centros de comunicação ou centros de produção, armazenagem, manipulação e distribuição de materiais inflamáveis ou combustíveis.

\subsection{Portugal}

Todas as regras e especificações sobre compartimentação horizontal podem ser verificadas no Decreto-Lei $n^{\circ} 220$ (2008) e na Portaria $n^{\circ} 1532$ (2008).

Portugal possui uma classificação padrão de desempenho da resistência ao fogo dos elementos, sendo atribuídas letras para cada tipo de resistência a um determinado TRRF. A classificação existente é apresentada na Tabela 2. 
Revista Científica do Corpo de Bombeiros Militar de Pernambuco

Seção 1 - Artigos Técnico Científicos

Artigo publicado no Vol.04 №10 - Edição de JUL a DEZ 2018 - ISSN 2359-4837(online)

Versão on-line disponível em: http://www.revistaflammae.com

Tabela 2 - Classificação dos elementos

\begin{tabular}{|c|l|}
\hline \multicolumn{2}{|c|}{ Classificação } \\
\hline$R$ & Establidade \\
\hline E & Estanqueidade \\
\hline I & Isolamento \\
\hline W & Radiação \\
\hline M & Ação mecânica \\
\hline C & Fechamento automático \\
\hline S & Passagem de fumaça \\
\hline P / PH & Fornecimento de energia \\
\hline G & Resitência ao fogo \\
\hline K & Capacidade de proteção ao fogo \\
\hline
\end{tabular}

Fonte: PORTUGAL, 2008a (adaptada)

Para exemplificar o disposto no decreto, apresenta-se alguns dos principais elementos construtivos e suas respectivas classificações:

- Elementos estruturais com função de compartimentação são classificados sempre como RE, REI, REI-M ou REW;

- $\quad$ Elementos de fachada devem ser E, El ou EW;

- Vedações de aberturas para passagem de conduítes são sempre E ou El;

- $\quad$ PCF devem ser E, El ou EW.

As classificações dos demais elementos podem ser verificados nos Quadros I a VI do Anexo II do Decreto-Lei n 220 (2008).

Todas as edificações são classificadas em quatro classes de risco de acordo com suas características específicas de uso, ou altura da edificação, ou número de pavimentos, ou área bruta, dentre outros, que podem ser verificados nos Quadros I a X do Anexo III do Decreto-Lei n 220 (2008).

Para a legislação portuguesa todos os edifícios devem ser feitos respeitando-se as exigências de compartimentação, independentemente do uso ou tamanho (exceto edificações unifamiliares), além disso, todos os pavimentos de uma edificação devem necessariamente constituir compartimentos distintos (com exceção de edifícios unifamiliares), ou seja, cada pavimento deve ser constituído por no mínimo um compartimento, 
independentemente do uso que a edificação terá. Por fim, para se ter a compartimentação de uma edificação deve-se garantir que:

- Cada elemento de compartimentação possui uma classificação própria de resistência ao incêndio, conforme apresentado anteriormente na Tabela 2, devendo ser utilizado de acordo com o TRRF da edificação até o um valor máximo determinado em norma para aquele tipo de elemento, por exemplo, existem pisos falsos com resistência de quinze ou trinta minutos, devendo ser utilizado o de trinta para estruturas com TRRF iguais ou superiores a trinta minutos;

- As paredes e os entrepisos de compartimentação, bem como os elementos estruturais, devem ser de classe REI;

- As PCF são dimensionadas de acordo com o TRRF da estrutura, existindo PCF com resistência de até duzentos e quarenta minutos ${ }^{3}$;

- Todas as aberturas entre compartimentos devem ser vedadas com selos corta fogo ou vedadores corta fogo de resistência equivalente à parede ou laje;

- Toda a tubulação deve estar protegida por dutos resistentes ao fogo providos de registros corta fogo automático;

- $\quad$ Os dutos de ar-condicionado e ventilação devem possuir registros corta fogo automático entre compartimentos distintos.

- As paredes exteriores do edifício devem ser de classe El ou REI com TRRF mínimo de $60 \mathrm{~min}$, tendo seus vãos guarnecidos por elementos de classe E com TRRF mínimo de $30 \mathrm{~min}$;

- Deve-se garantir distâncias mínimas horizontais entre aberturas para o exterior de compartimentos adjacentes, sendo previstas somente nos casos de fachadas anguladas, onde não se pode haver aberturas com distâncias menores que um metro do vértice (para ângulos entre $100^{\circ}$ e $135^{\circ}$ ) e menores que 1,5 metro (para ângulos de até $100^{\circ}$ ). A classe de resistência dessas

\footnotetext{
${ }^{3}$ É interessante lembrar que no Brasil, conforme apresentado no item anterior, as PCF são limitadas em cento e vinte minutos.
} 
Revista Científica do Corpo de Bombeiros Militar de Pernambuco Seção 1 - Artigos Técnico Científicos

Artigo publicado no Vol.04 №10 - Edição de JUL a DEZ 2018 - ISSN 2359-4837(online)

Versão on-line disponível em: http://www.revistaflammae.com

paredes se dá pela altura do edifício, possuindo TRRF mínimo de 30 min para edifícios de altura menor ou igual a $28 \mathrm{~m}$ e mínima de 60 min para edifícios maiores. Em ambos o TRRF deve ser de classe El;

- São previstas áreas máximas para os compartimentos.

Pode-se verificar na Tabela 3, que a legislação portuguesa determina as áreas máximas de compartimentação com base em apenas dois critérios: o tipo de uso da edificação e se o pavimento é um subsolo ou se é localizado acima do solo, exceto para edifícios industriais e depósitos para os quais a carga de incêndio também é considerada.

As áreas máximas de compartimentação apresentadas variam entre 400 e $12.800 \mathrm{~m}^{2}$ (além de áreas ilimitadas para alguns tipos de edificações).

\subsection{Inglaterra}

As regras e especificações sobre compartimentação horizontal para a Inglaterra (e País de Gales) estão presentes em The Building Regulations (2010) e no relatório External fire spread: building separation and boundary distances (BR 187, BRE 1991), que são válidas para a Inglaterra e País de Gales. 
Revista Científica do Corpo de Bombeiros Militar de Pernambuco Seção 1 - Artigos Técnico Científicos

Artigo publicado no Vol.04 №10 - Edição de JUL a DEZ 2018 - ISSN 2359-4837(online) Versão on-line disponível em: http://www.revistaflammae.com

Tabela 3 - Área Máxima de Compartimentação para o Portugal

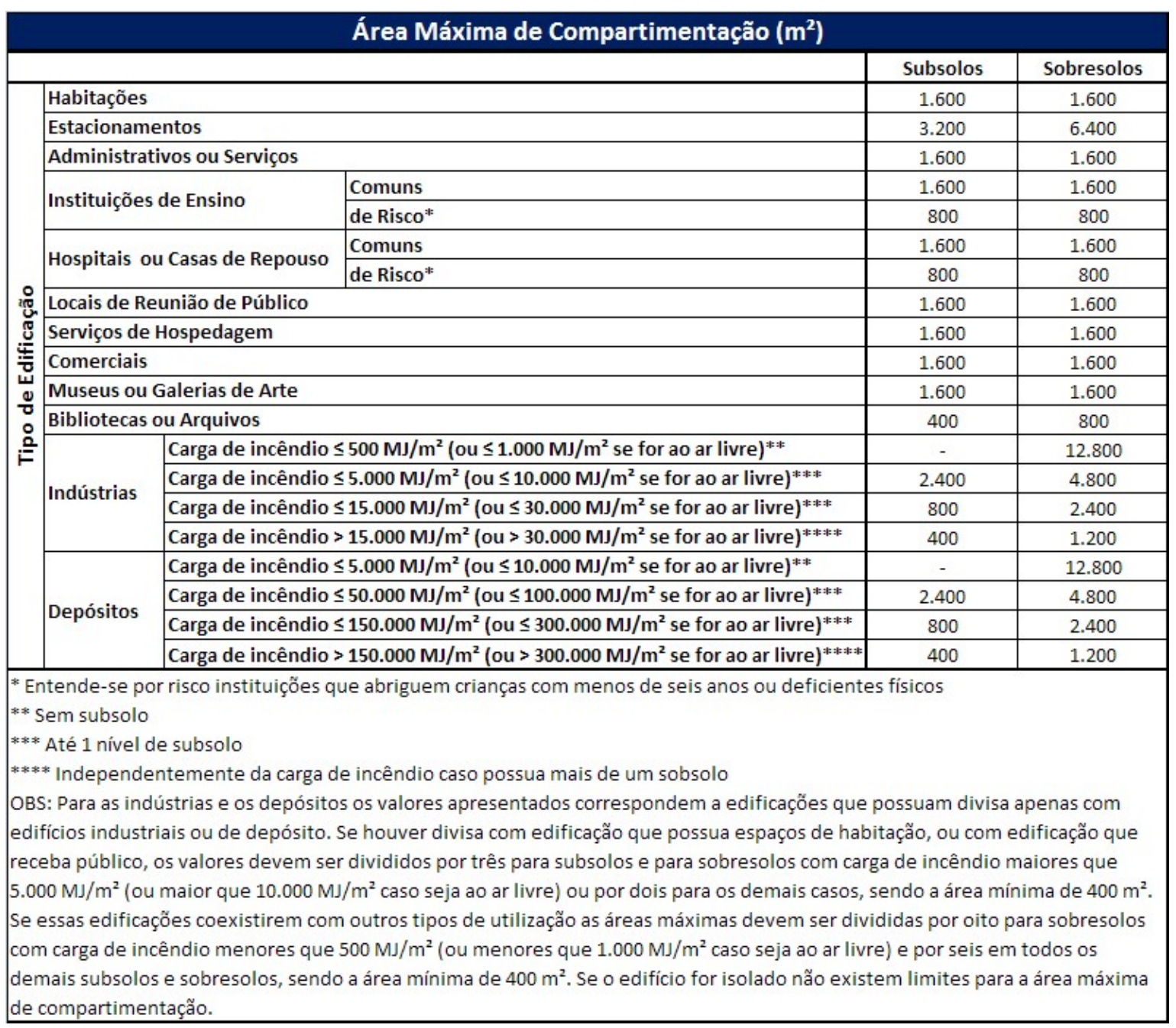

Fonte: PORTUGAL, 2008b (adaptada)

$\mathrm{Na}$ Inglaterra, a obrigatoriedade da compartimentação se dá de forma similar à obrigatoriedade em Portugal, onde todas as edificações devem ser compartimentadas (com exceção das edificações unifamiliares). Além dessa obrigatoriedade, existem algumas especificidades quanto às edificações geminadas, edificações de uso misto e outros usos específicos, mas que no geral só solicitam uma separação de compartimentos, ou seja, num mesmo edifício de uso misto uma área comercial e uma área residencial devem constituir compartimentos isolados, mesmo estando no mesmo pavimento. Além disso, a norma inglesa também se utiliza da classificação apresentada 
Revista Científica do Corpo de Bombeiros Militar de Pernambuco

Seção 1 - Artigos Técnico Científicos

Artigo publicado no Vol.04 №10 - Edição de JUL a DEZ 2018 - ISSN 2359-4837(online)

Versão on-line disponível em: http://www.revistaflammae.com

pela norma portuguesa para a classificação do TRRF (Tabela 2). Para que uma edificação seja considerada compartimentada, pelas normas inglesas, deve-se garantir que:

- As paredes e entrepisos de compartimentação, bem como os elementos estruturais, devem garantir estabilidade, estanqueidade e isolamento térmico (classe REI) para um tempo mínimo estipulado para cada tipo de edificação (TRRF);

- Outros elementos do edifício, tais como vigas, pilares, pisos, dutos, podem possuir TRRF distintos entre si, uma vez que seus valores são tabelados (tabelas A1 e A2 do Anexo B do The Building Regulations (2010));

- Todas as paredes de compartimentação ou lajes que separem os usos comercial e residencial devem ser de classe REI com TRRF mínimo de 60 min, qualquer outro piso deve seguir o TRRF da estrutura;

- Todo tipo de enclausuramento, independentemente do que está sendo enclausurado, deve ter TRRF mínimo de 30 min de classes E, El ou REl;

- As PCF devem ser dimensionadas para um mínimo equivalente ao TRRF da estrutura, possuindo um valor mínimo de resistência de vinte, trinta ou sessenta minutos, dependendo do tipo de edificação. A norma inglesa permite também a associação de duas portas corta fogo, no caso da presença de uma antecâmara, de forma a ampliar o tempo de resistência ao fogo total do grupo. Por exemplo, é possível que uma PCF 30 dê para um corredor com outra PCF 30 , sendo equivalente a uma PCF 60 . Deve-se lembrar que nesse último caso ambas as PCF devem possuir resistência mínima de trinta minutos; - As aberturas entre compartimentos, para passagem de tubulações e similares, devem possuir dimensões máximas de acordo com o material de constituição dos tubos, variando entre quarenta milímetros (para materiais combustíveis) até cento e sessenta milímetros (para matérias incombustíveis). Essas aberturas devem ser seladas com materiais que garantam a estanqueidade e o isolamento térmico da abertura por um tempo igual ou 
superior ao TRRF da edificação. Esses selantes podem ser feitos à base de cimento, gesso, fibra de vidro, escória de alto-forno, dentre outros;

- Todos os entroncamentos, shafts e tubulações que interligam compartimentos distintos devem ser protegidos com materiais resistentes ao fogo em harmonia com o TRRF do elemento de compartimentação no qual está alocado;

- Dutos de ventilação e ar-condicionado podem ser protegidos através de registros corta fogo automáticos, ou estando enclausurados por materiais com TRRF equivalente ao da estrutura, com TRRF mínimo de 30 min e classe E;

- Shafts específicos para o combate ao incêndio (com tubulações de chuveiros automáticos por exemplo) devem possuir enclausuramento de classe REI com TRRF mínimo de 60 min;

- Todas os elementos resistentes ao fogo de uma edificação, que não sejam de compartimentação, devem possuir TRRF mínimo de 30 min de classe REI.

- Deve-se garantir uma distância mínima entre aberturas horizontais presentes em compartimentos distintos, devendo-se utilizar um método tabular para sua obtenção. Esse método funciona simplificadamente da seguinte forma (

- )

a) Primeiro determinam-se todas as áreas não protegidas da fachada em análise do compartimento, sendo que esta área pode ser tanto um vão livre como uma parede que não seja de compartimentação;

b) Com todas as áreas não protegidas definidas, determina-se um retângulo imaginário, denominado área de exposição a risco, cujos extremos são as partes superiores, inferiores, mais à esquerda e mais à direita de todas as áreas desprotegidas;

c) Com esta área em mãos determina-se sua largura, altura e porcentagem de áreas não protegidas em relação à área total do retângulo; 
Revista Científica do Corpo de Bombeiros Militar de Pernambuco Seção 1 - Artigos Técnico Científicos

Artigo publicado no Vol.04 №10 - Edição de JUL a DEZ 2018 - ISSN 2359-4837(online)

Versão on-line disponível em: http://www.revistaflammae.com

d) Levam-se estes dados a uma tabela (sempre procurando o valor mais próximo superior ao real) e obtém-se a distância mínima desta área de exposição a risco para a área de exposição a risco do compartimento subsequente. As distâncias mínimas podem variar de 1 metro ao extremo de 55,5 metros.

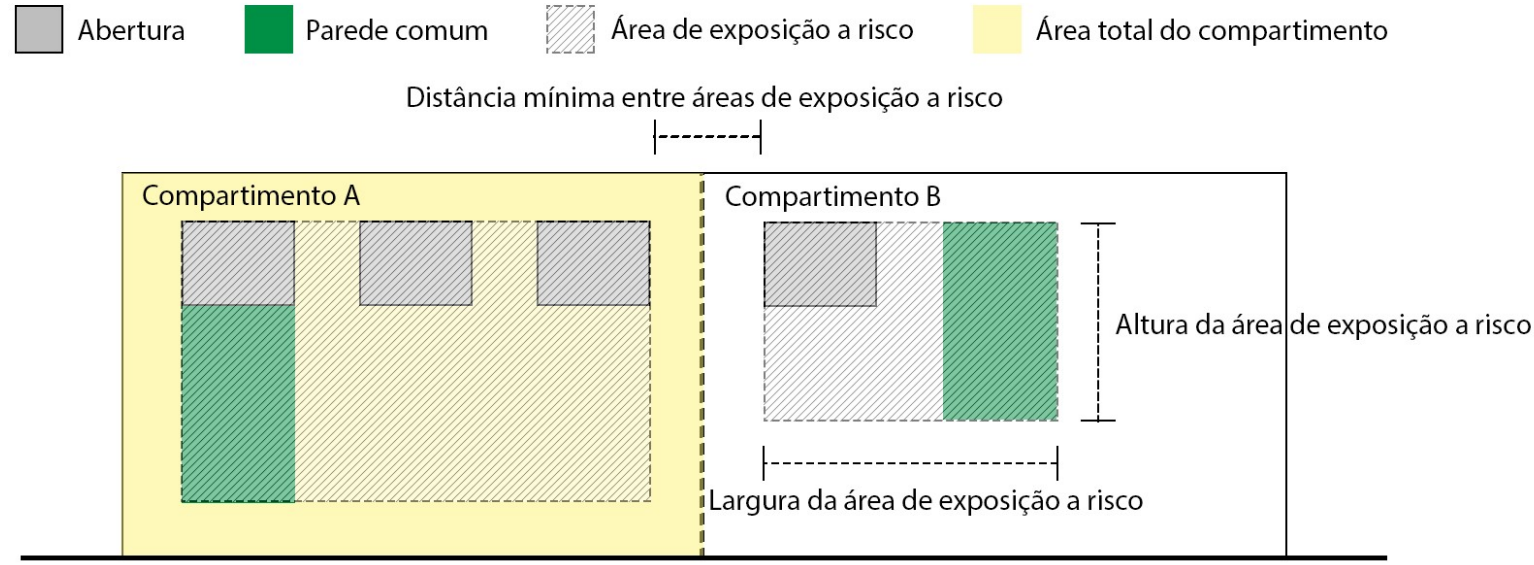

Figura 2 - Exemplo de distância entre áreas de exposição a risco de dois compartimentos

Fonte: Elaborada pelo autor

- Os compartimentos devem obedecer a área máxima prevista em norma de acordo com o tipo de edificação.

Como pode ser verificado na Tabela 4, a legislação inglesa determina a área máxima de um compartimento somente para utilizações consideradas não residenciais, com base na altura da edificação e na presença ou não de um sistema de chuveiros automáticos, cujas características podem ser encontradas no The Building Regulations (2010).

Verifica-se que as áreas máximas de compartimentação variam entre 2.000 e $40.000 \mathrm{~m}^{2}$ (além de áreas ilimitadas para alguns tipos de edificações). 


\section{Revista FLAMMAE}

Revista Científica do Corpo de Bombeiros Militar de Pernambuco Seção 1 - Artigos Técnico Científicos

Artigo publicado no Vol.04 №10 - Edição de JUL a DEZ 2018 - ISSN 2359-4837(online) Versão on-line disponível em: http://www.revistaflammae.com

Tabela 4 - Área Máxima de Compartimentação para a Inglaterra

\begin{tabular}{|c|c|c|c|c|c|c|c|}
\hline \multicolumn{8}{|c|}{ Área Máxima de Compartimentação $\left(\mathrm{m}^{2}\right)$} \\
\hline & & \multicolumn{3}{|c|}{ Sem Sprinklers } & \multicolumn{3}{|c|}{ Com Sprinklers } \\
\hline & & Térreo & $\leq 12 \mathrm{~m}$ & $>12 \mathrm{~m}$ & Térreo & $\leq 12 \mathrm{~m}$ & $>12 \mathrm{~m}$ \\
\hline \multirow{12}{*}{ 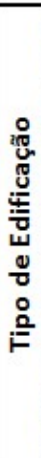 } & Habitações & * & * & * & * & * & * \\
\hline & Estacionamentos & Ilimitado & Ilimitado & Ilimitado & Ilimitado & Ilimitado & Ilimitado \\
\hline & Administrativos ou Serviços & Ilimitado & 2.000 & 2.000 & Ilimitado & 4.000 & 4.000 \\
\hline & Instituições de Ensino & * & * & * & * & * & * \\
\hline & Hospitais ou Casas de Repouso & * & * & * & * & $*$ & * \\
\hline & Locais de Reunião de Público & Ilimitado & 2.000 & 2.000 & Ilimitado & 4.000 & 4.000 \\
\hline & Serviços de Hospedagem & $*$ & * & $*$ & * & $*$ & $*$ \\
\hline & Comerciais & Ilimitado & 2.000 & 2.000 & Ilimitado & 4.000 & 4.000 \\
\hline & Museus ou Galerias de Arte & Ilimitado & 2.000 & 2.000 & Ilimitado & 4.000 & 4.000 \\
\hline & Bibliotecas ou Arquivos & Ilimitado & 2.000 & 2.000 & Ilimitado & 4.000 & 4.000 \\
\hline & Indústrias** & Ilimitado & 7.000 & 2.000 & Ilimitado & 14.000 & 4.000 \\
\hline & Depósitos & Ilimitado & 20.000 & 4.000 & Ilimitado & 40.000 & 8.000 \\
\hline \multicolumn{8}{|c|}{$\begin{array}{l}\text { * Estas edificações não possuem área máxima de compartimentação. Utiliza-se apenas um limite máximo de } \\
\text { deslocamento para fuga }\end{array}$} \\
\hline
\end{tabular}

Fonte: HER MAJESTY'S GOVERNMENT, 2006 (adaptada)

No caso em que não são determinadas áreas máximas de compartimentação é aplicado simplesmente uma distância máxima de fuga da edificação.

\subsection{Hong Kong}

Todas as regras e especificações sobre compartimentação horizontal podem ser verificadas em Code of Practice for Fire Safety in Buildings (2011).

Assim como a norma portuguesa, a norma honconguesa determina que, todos os edifícios devem ser feitos respeitando-se as exigências de compartimentação, ou seja, todas as edificações, independentemente do tipo de uso, área bruta ou mesmo número de pavimentos, devem possuir elementos de compartimentação em sua estrutura, seja internamente (caso exceda a área máxima do compartimento) ou externamente (quando próxima a outra edificação). 
A normatização de Hong Kong é bem simplificada, mas não menos segura ${ }^{4}$, sendo que, para garantir a compartimentação deve-se seguir os seguintes preceitos:

- Todas as paredes e entrepisos de compartimentação devem garantir estabilidade, estanqueidade e isolamento térmico para, no mínimo, o tempo de resistência ao fogo requerido para o edifício;

- Todas as aberturas e passagens entre compartimentos devem ser seladas por materiais que garantam a estanqueidade e o isolamento térmico da parede de compartimentação por um tempo mínimo equivalente ao TRRF da estrutura, paredes e lajes de compartimentação;

- As PCF devem possuir um tempo de resistência ao fogo equivalente ou superior ao TRRF da edificação em questão, podendo ser reduzido em 30 min caso existam chuveiros automáticos dos dois lados da porta.

- Da mesma forma que a norma portuguesa, existe uma distância mínima horizontal entre duas aberturas de dois compartimentos adjacentes (nesse caso sendo ou não da mesma edificação) dependendo da angulação da fachada. Para ângulos maiores que $135^{\circ}$ deve-se afastar a abertura no mínimo noventa centímetros da parede de compartimentação, entanto para ângulos menores do que $135^{\circ}$ a distância aumenta para cento oitenta centímetros. Esses valores só são aplicados a duas edificações distintas caso estejam afastados a menos de 1,8 metros entre si em um mesmo lote;

- Os compartimentos devem possuir uma área máxima.

A norma de Hong Kong é bem diferente das normas citadas anteriormente, pois, como pode ser verificado na Tabela 5 , a área máxima de compartimentação depende única e exclusivamente do tipo de uso que a edificação possuirá.

\footnotetext{
${ }^{4} \mathrm{Na}$ realidade a norma honconguesa acaba sendo até mais rígida que as demais normas, uma vez que a falta de subdivisões acarreta a utilização de TRRF mais alto para edificações de menor porte.
} 
Revista Científica do Corpo de Bombeiros Militar de Pernambuco

Seção 1 - Artigos Técnico Científicos

Artigo publicado no Vol.04 №10 - Edição de JUL a DEZ 2018 - ISSN 2359-4837(online)

Versão on-line disponível em: http://www.revistaflammae.com

Tabela 5 - Área Máxima de Compartimentação para Hong Kong

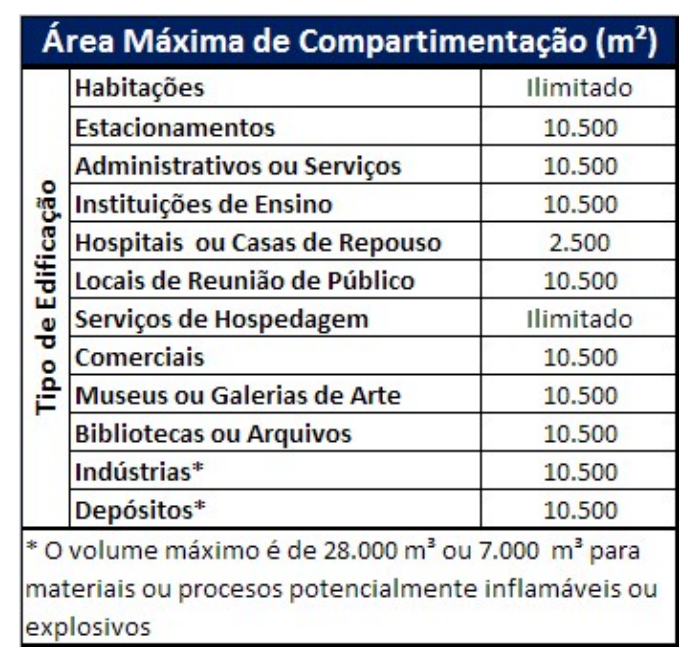

Fonte: BUILDINGS DEPARTMENT, 2012 (adaptada)

Os grupos das indústrias e dos depósitos, além de uma área máxima de compartimentação possuem também um volume máximo de compartimentação, que varia entre 7.000 e $28.000 \mathrm{~m}^{3}$.

As áreas máximas de compartimentação apresentadas variam entre 2.500 e $10.500 \mathrm{~m}^{2}$ (além de áreas ilimitadas para alguns tipos de edificações).

\subsection{Estados Unidos}

As regras e especificações sobre compartimentação horizontal podem ser verificadas no International Building Code 2012.

Diferentemente de todas as normas apresentadas neste artigo, a norma norte-americana subdivide as edificações não só pelo tipo de atividade a que se destina, como também pelas características e materiais usados em suas construções.

Existem cinco tipos de construções em que, simplificadamente, podemos considerar:

- Tipo I: São construções, inclusive a cobertura, cujas estruturas e paredes externas e internas são feitas de materiais incombustíveis, que devem respeitar determinados tempos requeridos de resistência ao fogo (TRRF). Por 
Revista Científica do Corpo de Bombeiros Militar de Pernambuco

Seção 1 - Artigos Técnico Científicos

Artigo publicado no Vol.04 №10 - Edição de JUL a DEZ 2018 - ISSN 2359-4837(online)

Versão on-line disponível em: http://www.revistaflammae.com

exemplo, a estrutura principal deve resistir a 180 min do incêndio-padrão (considerada construção tipo IA) ou 120 min (considerada construção tipo IB).

- $\quad$ Tipo II: São construções semelhantes ao Tipo I, porém com TRRF mais brandos. Por exemplo, a estrutura principal deve resistir a $60 \mathrm{~min}$ (considerada construção tipo IIA) ou isenta de verificação estrutural (considerada construção tipo IIB).

- Tipo III: São construções compostas por paredes externas incombustíveis e elementos construtivos no interior podendo ser combustíveis, respeitando determinados TRRF. Por exemplo, a estrutura principal deve respeitar $60 \mathrm{~min}$ (considerada construção tipo IIIA) ou isenta de verificação estrutural (considerada construção tipo IIIB).

- $\quad$ Tipo IV: São construções compostas por paredes externas de materiais incombustíveis e interiormente, de madeira de alta densidade possuindo características peculiares. Por serem pouco utilizadas no Brasil, não se entrará no mérito das exigências para este tipo de construção

- $\quad$ Tipo V: São construções compostas por qualquer material, que não a defina como um dos tipos citados anteriormente.

Para o código americano todas as edificações devem ser compartimentadas e cada compartimento deve ser considerado como uma edificação distinta, sendo uma visão mais radical e bem diferente das apresentadas nas outras normas. Sendo que, para que seja garantida a compartimentação, deve-se seguir os seguintes princípios:

- Todas as paredes de compartimentação, assim como os elementos estruturais, devem garantir sua estabilidade, estanqueidade e isolamento térmico para um determinado TRRF, variando não só de acordo com o tipo e uso da edificação, como também para cada elemento construtivo distinto;

- As PCF devem ser dimensionadas para resistirem no mínimo o mesmo tempo que o TRRF da estrutura em que ela está sendo instalada; 
Revista Científica do Corpo de Bombeiros Militar de Pernambuco Seção 1 - Artigos Técnico Científicos

Artigo publicado no Vol.04 №10 - Edição de JUL a DEZ 2018 - ISSN 2359-4837(online)

Versão on-line disponível em: http://www.revistaflammae.com

- Uma vez que para a norma americana cada compartimento deve ser considerado como uma edificação distinta, as selagens das ligações entre compartimentos devem ser realizadas com materiais que garantam a estanqueidade e o isolamento térmico por um período mínimo equivalente ao TRRF da parede em questão;

- As aberturas existentes para o exterior de um compartimento são limitadas a uma porcentagem da área da parede, variando de acordo com o tipo de construção e de sua distância para outra edificação. Em alguns casos específicos, edificações com chuveiros automáticos podem ter sua área máxima de abertura para o exterior ampliada;

- Todos os dutos de ventilação e ar-condicionado devem ser protegidos por registros corta fogo automáticos.

- A parede de compartimentação horizontal deve, por padrão, se projetar para o exterior da edificação por, no mínimo, 45,7 centímetros, garantindo assim a compartimentação horizontal. Essa projeção pode, no entanto, ser dispensada em alguns casos específicos, tais como:

a) Se a parede externa for uma parede de compartimentação resistente a no mínimo 60 minutos com no mínimo 1,22 metros para cada lado e que qualquer abertura deve possuir proteção de no mínimo 45 minutos;

b) Se a parede externa for de material incombustível com no mínimo 1,22 metros para cada lado;

c) Caso a edificação possua chuveiros automáticos.

- No caso de fachadas anguladas de até 180 graus, provenientes de compartimentos distintos, deve-se criar uma faixa de proteção com no mínimo 1,22 metros em cada empena, sendo que esta faixa deve possuir TRRF de no mínimo 60 min e todas as aberturas devem possuir proteção com TRRF de no mínimo 45 min;

- A norma norte-americana não se refere diretamente a áreas limites de compartimentação horizontal, mas sim a áreas limites de pavimento, que por 
Revista Científica do Corpo de Bombeiros Militar de Pernambuco

Seção 1 - Artigos Técnico Científicos

Artigo publicado no Vol.04 №10 - Edição de JUL a DEZ 2018 - ISSN 2359-4837(online)

Versão on-line disponível em: http://www.revistaflammae.com

similaridade aos demais países, os autores chamarão de áreas de compartimentação. Essas áreas de compartimentação horizontal fazem parte de um conjunto de limites que, como um todo, o IBC considera adequado à segurança contra incêndio para o tipo considerado de construção. Esse conjunto é formado limites de área, tipo de construção, conforme definido anteriormente que, por sua vez, tem certos TRRF preestabelecidos, altura do edifício e o uso.

Essas áreas de compartimentação horizontal fazem parte de um conjunto de limites construtivos que, como um todo, o IBC considera adequado à segurança contra incêndio para cada tipo de construção. Esse conjunto de limites é formado por: limites de área; tipo de construção (que possuem TRRF específicos); altura do edifício; tipo de uso da edificação.

As áreas máximas de compartimentação, conforme pode ser visto na Tabela 6, variam entre 511 e $7.339 \mathrm{~m}^{2}$ (permitindo áreas ilimitadas em algumas situações). O número máximo de andares varia entre 2 e 11 (ou ilimitado em alguns tipos construtivos e atividades). As alturas máximas variam entre 12,2 e $48,8 \mathrm{~m}$ (ou ilimitado para o caso de edificações do tipo IA).

\section{DISCUSSÃO E ANÁLISES}

Após serem comparadas as normas dos países selecionados percebese que o principal consenso encontrado foi a definição de compartimentação, além do fato da preocupação com a selagem de vãos de passagem de tubulações ser sempre similar.

Por mais que os tipos de edificações não sejam agrupados sempre da mesma forma nas diversas normas, foi possível verificar que a ideia geral e as características básicas são sempre as mesmas.

O ponto divergente mais evidente foi a rigidez presente nas legislações, sendo que, de forma resumida temos: 
Revista Científica do Corpo de Bombeiros Militar de Pernambuco Seção 1 - Artigos Técnico Científicos

Artigo publicado no Vol.04 №10 - Edição de JUL a DEZ 2018 - ISSN 2359-4837(online)

Versão on-line disponível em: http://www.revistaflammae.com

- Portugal possui uma legislação bem direcionada para cada tipo de elemento, possuindo valores e classes de TRRF para cada elemento. Fora isso não existem muitas exceções para TRRF específicos para dutos, PCF e similares;

A Inglaterra apresenta diversos valores mínimos de resistência para elementos de compartimentação, como enclausuramentos, PCF, dutos de ventilação e similares. Isso ocorre pelo fato da legislação inglesa ser mais branda quanto à determinação do TRRF das paredes e lajes de compartimentação, uma vez que possuem seus valores muitas vezes reduzidos pelo uso de chuveiros automáticos em compartimentos;

- Hong Kong possui a legislação com menor número de exceções, tendo o valor do TRRF de todos es elementos de compartimentação em harmonia com o TRRF da estrutura. A única exceção é a da redução do TRRF da PCF no caso de existirem chuveiros automáticos dos dois lados da porta;

- $\quad$ Os Estados Unidos possuem uma norma extremamente rígida, uma vez que consideram cada compartimento como sendo uma edificação isolada, não possuindo muitas exceções, assim como a norma de Hong Kong; 2003. 
Revista FLAMMAE

Revista Científica do Corpo de Bombeiros Militar de Pernambuco

Seção 1 - Artigos Técnico Científicos

Artigo publicado no Vol.04 №10 - Edição de JUL a DEZ 2018 - ISSN 2359-4837(online)

Versão on-line disponível em: http://www.revistaflammae.com

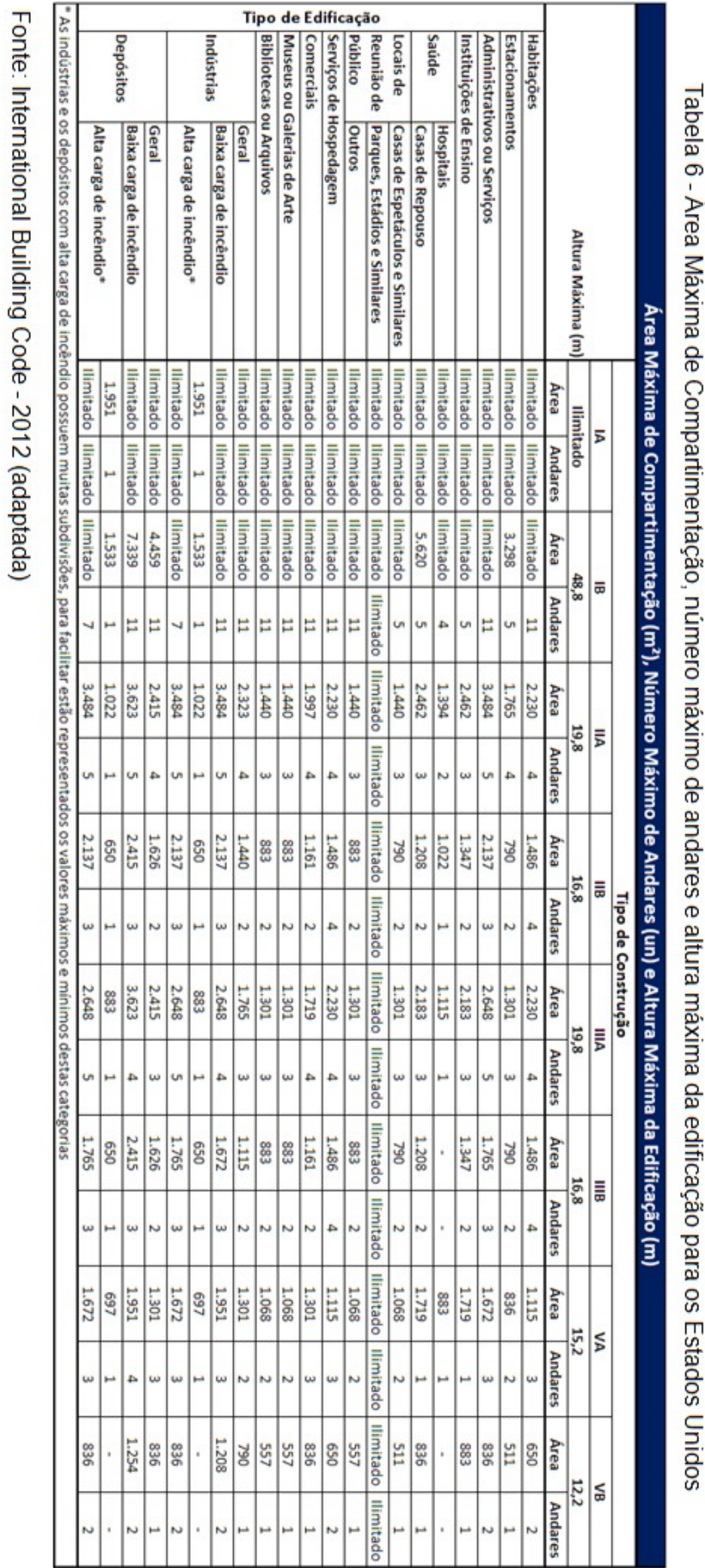


- A norma Brasileira é de longe a norma com maior número de exceções e especificidades, possuindo valores específicos de TRRF para PCF, selagens, dutos e passagens de ventilação, prumadas de ventilação dentre outros, que muitas vezes são bem superiores à exigida para as paredes e entrepisos de compartimentação. Um exemplo claro é o do caso de uma PCF que dê acesso a um pavimento, devendo possuir resistência mínima de 90 min, enquanto a edificação pode ter uma resistência de apenas $30 \mathrm{~min}$. Por sua vez, é possível ter uma PCF com 120 min em uma edificação com TRRF igual a 240 min.

Nota-se também que há países (Portugal e Hong Kong) em que a compartimentação horizontal é obrigatória para todos os edifícios, independentemente de seu uso, enquanto em outros países, há dispensa de compartimentação para alguns usos. No Brasil, por exemplo, não é obrigatória a compartimentação de edifícios residenciais, enquanto em Portugal e Hong Kong é obrigatório.

Além disso é possível notar também que os critérios para a determinação das áreas máximas de um compartimento variam muito:

- Hong Kong possui o método mais simplificado, onde cada tipo de uso recebe uma área ou volume máximo de compartimentação, independentemente das características gerais do edifício. Em contrapartida, para eles, toda e qualquer edificação, independentemente de seu uso, possui compartimentação vertical e horizontal, porém as áreas máximas são extremamente elevadas se comparadas aos outros países, o que pode acabar se tornando desvantajoso para a segurança contra o incêndio;

- Em Portugal as áreas máximas de compartimentação variam, em geral, pelo tipo de uso do edifício e pelo pavimento ser acima ou abaixo do nível do terreno. Por mais que, à primeira vista, possa parecer um método mais simplificado, uma vez que a altura da edificação não influencia em sua área máxima, a normatização portuguesa é uma das mais rígidas, já que todas as edificações possuem obrigatoriamente compartimentação vertical e horizontal 
(assim como em Hong Kong). Outro fator importante a ser levantado em conta é que esse método é menos econômico do que o brasileiro, uma vez que obriga edificações mais baixas a terem compartimentos menores o que, por outro lado, é vantajoso no âmbito da segurança contra o incêndio e na preservação de vidas;

- O Brasil possui um dos critérios mais específicos e detalhados de todos, teoricamente possui uma legislação mais rígida do que a de Hong Kong, pois além de possuir áreas menores de compartimentação horizontal, quanto mais alta a edificação maior é a redução da área requerida do compartimento. Porém, na realidade a norma acaba sendo muito mais branda, uma vez que o decreto do Estado de São Paulo n 56.819 de 2011 permite a eliminação da área máxima de compartimentação para praticamente todas as edificações (com altura inferior a trinta metros), em troca do uso de chuveiros automáticos;

- A Inglaterra possui um sistema semelhante ao brasileiro. As áreas máximas são determinadas de acordo com o uso e a altura da edificação, porém é feita de forma muito mais simplificada, uma vez que só divide as edificações em três categorias de altura, enquanto o Brasil possui seis classificações. Outro ponto importante é que o código inglês dá muito mais ênfase que a norma brasileira quando se trata de chuveiros automáticos. $\mathrm{Na}$ legislação brasileira temos um decreto estadual que menciona a possibilidade da substituição das áreas máximas, porém como simples nota de rodapé, enquanto a norma inglesa coloca lado a lado a utilização ou não dos chuveiros automáticos, demonstrando um claro destaque ao uso de tais dispositivos (explicado, possivelmente, por um uso mais extensivo do sistema no país, se comparado ao Brasil). Por último, é importante frisar uma diferença crucial no uso dos chuveiros automáticos, pois enquanto no Brasil seu uso elimina as áreas máximas de compartimentação, na Inglaterra eles apenas ampliam sua área, deixando claro a importância dada para a compartimentação horizontal pelos ingleses; 
Revista Científica do Corpo de Bombeiros Militar de Pernambuco

Seção 1 - Artigos Técnico Científicos

Artigo publicado no Vol.04 №10 - Edição de JUL a DEZ 2018 - ISSN 2359-4837(online)

Versão on-line disponível em: http://www.revistaflammae.com

- Os Estados Unidos possuem um sistema de classificação muito diferente dos países analisados anteriormente. Eles levam em conta um conjunto de características para definir se um edifício é seguro em situação de incêndio, em especial o material de construção. Por outro lado eles desconsideram a altura da edificação na definição da área máxima de compartimentação e, simultaneamente, definem uma altura máxima da edificação de acordo com suas características construtivas e tipo de uso. Esse comportamento pode ser explicado, possivelmente, pelo fato de que nos Estados Unidos utiliza-se muito a construção em madeira, além de possuir um largo histórico de incêndios, o que os deve ter levado a analisar de uma forma diferenciada as edificações em situação de incêndio.

Fora isso, a visão da distância mínima horizontal entre vãos de compartimentos distintos é bem diferente:

- No Brasil exige-se uma distância mínima de dois metros, ou uma prolongação da parede de compartimentação de ao menos noventa centímetros;

- Portugal determina uma faixa de proteção nos extremos dos compartimentos de acordo com a angulação da fachada, variando entre um metro e um metro e meio. Por outro lado, não são definidas distâncias mínimas entre vãos caso exista uma angulação maior do que $135^{\circ}$ entre as fachadas dos compartimentos;

- Hong Kong possui uma norma muito semelhante à portuguesa, porém a faixa de proteção possui valores mínimos de noventa e cento e oitenta centímetros, de acordo com a angulação da fachada. Assim como em Portugal, a faixa de proteção é inexistente no caso de angulações superiores a $135^{\circ}$ entre as fachadas;

- A Inglaterra possui a norma mais complexa de afastamento entre vãos dentre todos os analisados, considerando a área total das aberturas existentes na fachada, com valores entre 1 e 55,5 metros; 
- Os Estados Unidos possuem, novamente, a normatização mais diferenciada. Sua norma exige a projeção de paredes de compartimentação por no mínimo $45,7 \mathrm{~cm}$ da fachada, podendo ser substituída por faixas de proteção semelhantes às especificadas em Portugal e Hong Kong, porém com valor mínimo de 1,22 metros e características específicas de TRRF. Sendo que essa faixa de proteção é exigida em fachadas anguladas com até $180^{\circ}$. É importante frisar que no caso de edificações com chuveiros automáticos a distância horizontal entre aberturas deixa de ser exigida.

\section{CONSIDERAÇÕES FINAIS}

Não há norma brasileira sobre compartimentação e o intuito deste artigo foi fornecer base científica ou de consenso de outras sociedades, visando contribuir para o entendimento do tema e colaborar para a elaboração de uma futura norma brasileira.

Ao analisar os códigos do Brasil, Portugal, Inglaterra, Hong Kong e Estados Unidos, percebe-se que, de forma geral, as definições relacionadas à compartimentação são virtualmente idênticas. Todos os países analisados classificam as edificações de acordo com seu uso, embora varie o nível de detalhamento.

No entanto, há diferenças entre exigências, tanto da própria obrigatoriedade, quanto de suas dimensões máximas. Há países em que a compartimentação horizontal é obrigatória para todos os edifícios, enquanto em outros, há dispensa de compartimentação para alguns usos.

Nota-se também que os critérios para a determinação das áreas máximas de um compartimento variam muito, desde considerações simples até muito complexas. Mesmo os países considerados avançados no quesito segurança contra incêndio possuem visões muito diferentes ao abordar o assunto, fazendo com que cada um busque critérios próprios para definir 
Revista Científica do Corpo de Bombeiros Militar de Pernambuco

Seção 1 - Artigos Técnico Científicos

Artigo publicado no Vol.04 №10 - Edição de JUL a DEZ 2018 - ISSN 2359-4837(online)

Versão on-line disponível em: http://www.revistaflammae.com

valores, como, a área máxima de compartimentação, provavelmente em função dos costumes ou históricos locais.

O que se espera é que os pesquisadores brasileiros procurem um consenso, com o auxílio daquilo aqui fornecido e de outros estudos e elaborem uma norma brasileira sobre compartimentação, visto a inexistência de tal obrigatoriedade em alguns estados brasileiros.

\section{REFERÊNCIAS BIBLIOGRÁFICAS}

ASSOCIAÇÃO BRASILEIRA DE NORMAS TÉCNICAS (ABNT). NBR 5628: Componentes construtivos estruturais - Determinação da resistência ao fogo. Rio de Janeiro, 2001a. 13 p.

NBR 6479: Portas e vedadores - Determinação da resistência ao fogo - Método de ensaio. Rio de Janeiro, 1992. 8 p.

NBR 10636: Paredes divisórias sem função estrutural - Determinação da resistência ao fogo - Método de ensaio. Rio de Janeiro, 1989. 7 p.

. NBR 11742: Porta corta-fogo para saída de emergência. Rio de Janeiro, 2003b. 19 p.

. NBR 13860: Glossário de termos relacionados com a segurança contra incêndio. Rio de Janeiro, 1997. 10 p.

. NBR 14323: Projeto de estruturas de aço e de estruturas mistas de aço e concreto de edifícios em situação de incêndio. Rio de Janeiro, 2013. 75 p.

NBR 14432: Exigências de resistência ao fogo de elementos construtivos de edificações. Rio de Janeiro, 2001b. 15 p.

. NBR 15200: Projeto de estruturas de concreto em situação de incêndio. Rio de Janeiro, 2012. 54 p.

BUILDINGS DEPARTMENT (Hong Kong). Code of Practice for Fire Safety in Buildings 2011. Hong Kong, 2012.

BUILDING RESEARCH ESTABLISH.(BRE).BR 187, BRE 1991. External fire spread: building separation and boundary distances. Borehamwood: R.E.H.Read, 1991. 
Revista Científica do Corpo de Bombeiros Militar de Pernambuco Seção 1 - Artigos Técnico Científicos

Artigo publicado no Vol.04 №10 - Edição de JUL a DEZ 2018 - ISSN 2359-4837(online)

Versão on-line disponível em: http://www.revistaflammae.com

CORPO DE BOMBEIROS DA POLÍCIA MILITAR DO ESTADO DE SÃO PAULO (CBPMESP). Instrução Técnica $N^{\circ} 3$ I 2015:Terminologia de segurança contra incêndio. São Paulo: Secretaria de Estado dos Negócios da Segurança Pública, 2015a.

- Instrução Técnica $\mathbf{N}^{\circ} 7$ / 2015: Separação entre edificações (isolamento de risco). São Paulo: Secretaria de Estado dos Negócios da Segurança Pública, 2015b.

. Instrução Técnica $N^{\circ} 9$ / 2015: Compartimentação horizontal e compartimentação vertical. São Paulo: Secretaria de Estado dos Negócios da Segurança Pública, 2015c.

COSTA, C. N. Dimensionamento de elementos de concreto armado em situação de incêndio. 2008. 724 p. Tese (Doutorado em Engenharia Civil) Escola Politécnica, Universidade de São Paulo, São Paulo, 2008.

COSTA, C. N.; ONO, R.; SILVA, V. P. A importância da compartimentação e suas implicações no dimensionamento das estruturas de concreto em situação de incêndio. In: CONGRESSO BRASILEIRO DO CONCRETO, 49., 2005, Olinda. Anais... São Paulo: IBRACON, 2005. v. III. p. III1-III26.

GILL, A. A.; NEGRISOLO, W.; OLIVEIRA, S. A. Aprendendo com os grandes incêndios. In: SEITO, A. I.; GILL, A. A.; PANNONI, F. D.; ONO, R.; SILVA, S. B.; DEL CARLO, U.; SILVA, V. P. (Ed.). A segurança contra incêndio no Brasil. São Paulo: Projeto Editora, 2008. cap. 3, p. 19-33.

HER MAJESTY'S GOVERNMENT. The Building Regulations 2010 - Fire Safety. HMSO: London, 2006.

INTERNATIONAL CODE COUNCIL (ICC). 2012 International Building Code. 1th Edition. U.S.A.: ICC, 2011.

MARCATTI, J.; COELHO FILHO, H. S.; BERQUÓ FILHO, H. S. Compartimentação e afastamento entre edificações. In: SEITO, A. I.; GILL, A. A.; PANNONI, F. D.; ONO, R.; SILVA, S. B.; DEL CARLO, U.; SILVA, V. P. (Ed.). A segurança contra incêndio no Brasil. São Paulo: Projeto Editora, 2008. cap. 3, p. 169-179. 
Revista Científica do Corpo de Bombeiros Militar de Pernambuco Seção 1 - Artigos Técnico Científicos

Artigo publicado no Vol.04 №10 - Edição de JUL a DEZ 2018 - ISSN 2359-4837(online)

Versão on-line disponível em: http://www.revistaflammae.com

NATIONAL FIRE PROTECTION ASSOCIATION (NFPA). NFPA 80A: Recommended Practice for Protection of Buildings from Exterior Fire Exposures. Quincy: NFPA, 1996.

PORTUGAL (País). Decreto-Lei $n^{\circ}$ 220/2008, de 12 de novembro. Regime Jurídico da Segurança Contra Incêndio em Edifícios. Diário da República, Ministérios da administração interna e das obras públicas, transportes e comunicações, Lisboa, p. 67, 2008a.

PORTUGAL (País). Portaria no 1532/2008, de 29 de dezembro: Regulamento Técnico de segurança Contra Incêndio (RT-SCIE). Diário da República, Ministérios da administração interna e das obras públicas, transportes e comunicações, Lisboa, p. 244, 2008b.

SÃO PAULO (Estado). Decreto $n^{\circ} 56.819$ de 10 de março de 2011: Institui o Regulamento de Segurança contra incêndio das edificações e área de risco no Estado de São Paulo e estabelece outras providências. Diário Oficial do Estado de São Paulo, Poder Executivo, São Paulo, p. 43, 10 mar. 2011.

SILVA, V. P. Projeto de estruturas de concreto em situação de incêndio. São Paulo: Blücher, 2012.

SILVA, V. P. Segurança contra incêndio em edifícios. São Paulo: Blücher, 2014.

SILVA, V. P.; COSTA, C. N.; MELÃO, A.. Procedure for decreasing the required time for fire resistance of the multistory buildings. Revista Ibracon de Estruturas e Materiais-RIEM, v. 10, p. 1141-1162, 2017.

\section{AGRADECIMENTOS}

Os autores agradecem à CAPES Coordenação de Aperfeiçoamento de Pessoal de Nível Superior, ao CNPq - Conselho Nacional de Pesquisa e Desenvolvimento Científico e à FAPESP Fundação de Amparo à Pesquisa do Estado de São Paulo. 